\section{Olanzapine-induced akathisia in OCD}

Sir - Akathisia is a distressing side-effect of neuroleptic medication. As an atypical neuroleptic, olanzapine is less likely to cause extrapyramidal side-effects, and the prevalence of akathisia after treatment with olanzapine in clinical trials of patients with schizophrenia was about the same as after treatment with clozapine, at $6.3 \% .{ }^{1}$ There have been case reports of akathisia in patients with schizophrenia being treated with olanzapine, but none of akathisia in patients with other disorders receiving olanzapine. We present a case of akathisia in a patient with obsessive-compulsive disorder (OCD) receiving olanzapine. Akathisia resolved on discontinuation of olanzapine, and reappeared when the drug was recommenced.

\section{Case report}

A 30 year-old woman with severe OCD was admitted to hospital for treatment. Her symptoms included obsessive thoughts that "something bad will happen", and compulsions designed to ward off harm. These included performing bathroom rituals, walking in and out of doors, and writing the letter "n" (for "not") on walls. She also had repeating, counting, and checking compulsions. Rituals were repeated four times or in multiples of four. At its most severe, the disorder necessitated that the patient stay in the bathroom all night, performing endless rituals.

There were comorbid depressive symptoms intermittently. The patient did not have tics. There was no other psychiatric history, no medical history, and no family history of OCD or Gilles de la Tourette syndrome.

Initial treatment with clomipramine could not be tolerated by the patient who experienced severe side-effects. Paroxetine $50 \mathrm{mg}$ daily was unhelpful. At the time of her admission to hospital, the Yale-Brown Obsessive Compulsive Scale (YBOCS) score was 32. The paroxetine dose was maintained at $50 \mathrm{mg}$, and olanzapine $10 \mathrm{mg}$ was added. This was titrated to $15 \mathrm{mg}$ and after two weeks of treatment there was a dramatic response with marked improvement of all OCD symptoms. YBOCS score was eight.

After three weeks of treatment however, severe akathisia developed, the patient scoring 24 on the Hillside Akathisia Scale (subjective and objective subscale scores of 12 and 12 respectively). There were no other extrapyramidal symptoms. Treatment with benztropine was unhelpful, and the patient self-discontinued olanzapine. All OCD symptoms returned, and the patient was as disabled as ever.

Olanzapine was recommenced, again with good effect on the OCD symptoms, and akathisia, which reappeared after a few days, was successfully treated with propranolol, $20 \mathrm{mg}$ bid. OCD symptoms remain in remission.

Significant OCD symptoms persist in $40 \%-60 \%$ of patients after a trial of a serotonin reuptake inhibitor (SRI). ${ }^{2}$ There is evidence to suggest a role for antipsychotic drugs in the pharmacologic management of OCD. In a study of fluvoxamine augmented with the typical neuroleptic haloperidol, improvement occurred in $65 \%$ of patients with refractory OCD. ${ }^{3}$

There is less data regarding the use of atypical neuroleptics in refractory OCD. Preliminary reports suggest that risperidone might alleviate OCD symptoms when added to an SRI, and in one study risperidone in addition to an SRI led to a significant improvement in $50 \%$ of SM-refractory OCD patients.

Olanzapine, another atypical neuroleptic, has been reported to improve $O C D$ symptoms when added to fluoxetine in one case report. ${ }^{4}$ In clinical trials of olanzapine in patients with schizophrenia, akathisia has been reported. ${ }^{1}$ There have been only two reports describing individual cases of olanzapine-induced akathisia, ${ }^{5,6}$ and these also occurred in patients with schizophrenia.

To our knowledge, this is the first report of olanzapineinduced akathisia in OCD. SRIs have independently been reported to cause akathisia, ${ }^{7}$ however SRI-induced akathisia was felt to be unlikely in this case as the patient had been taking paroxetine for four months prior to the addition of olanzapine, without ill-effect.

In view of the very dramatic response to olanzapine in our patient, a role for olanzapine in the treatment of patients with refractory OCD is further suggested. Our report highlights both the advantages of a trial of an atypical neuroleptic in OCD patients, and the fact that atypical neuroleptics may cause akathisia in patients with OCD, as in patients with schizophrenia. Since neuroleptic-induced akathisia is frequently associated with compliance difficulties, it is important to consider the akathisia risk of the newer antipsychotic drugs, even though it is much lower than that found with typical neuroleptics.

\section{Richelle M Kirrane, Senior Registrar in Psychiatry, Stewart's Hospital, Palmerstown, Dublin 20, Ireland.}

References

1. Beasley CM, Tollefson G, Tran P, Satterlee W, Sanger T, Hamilton S. Olanzapine versus placebo and haloperidol: acute phase results on the North American double-blind olanzapine trial. Neuropsychopharmacology 1996; 14: 111-23

2. Goodman WK, Ward HE, Murphy TK. Biologic approaches to treatment refractory obsessive-compulsive disorder. Psychiatr Ann 1998; 28: 641-9. 3. McDougle CJ, Goodman WK, Leckman JF, Lee NC, Heninger GR, Price LH. Haloperidol addition in fluvoxamine-refractory obsessive-compulsive disorder: a double-blind placebo-controlled study in patients with and without tics. Arch Gen Psychiatry 1994; 51: 302-8.

4. Potenza MN, Wasylink S, Longhurst JG, Neill Epperson C, McDougle CJ. Olanzapine augmentation of fluoxetine in the treatment of refractory obsessivecompulsive disorder. J Clin Psychopharmacol 1998; 18: 423-4.

5. Kurzthaler I, Hummer M, Kohl C, Miller C, Fleischhacker WW. Propranolol treatment of olanzapine-induced akathisia. Am J Psychiatry 1997; 154: 1316. 6. Jauss M, Schroder I, Pantel J, Bachmann S, Gerdsen I, Mundt C. Severe akathisia during olanzapine treatment of acute schizophrenia. Pharmacopsychiat 1998; 31: 146-8.

7. Sachdev P. The epidemiology of drug-induced akathisia: part I. Acute akathisia. Schiz Bull 1995; 21: 431-49.

Letters to the Editor should be addressed to:

$$
\begin{gathered}
\text { The Editor } \\
\text { Irish Journal of Psychological Medicine } \\
25 \text { Adelaide Street } \\
\text { Dun Laoghaire } \\
\text { Co Dublin. }
\end{gathered}
$$$$
\text { Fax: 01-2807076 }
$$

Email: mail@medmedia.ie 